\title{
Impact of Volume-Based Drug Procurement Policy on Drug Use Structure of Chinese Public Medical Institutions: A Difference-in-Difference Analysis of Nine Pilot Cities and Twelve Non-pilot Provinces
}

Jiancheng Lu

Jilin University

Ying Yang

Wuhan University

Hongfei Long

Wuhan University

Jing Wang

National Health Commission of the People's Republic of China

Yuan Shen

National Health Commission of the People's Republic of China

Dan Cui

Wuhan University

Zongfu Mao ( $\sim$ zfmao@whu.edu.cn )

Wuhan University

Jinghua Li

Jilin University

\section{Research Article}

Keywords: National Centralized Drug Procurement (NCDP), volume-based drug procurement, 4+7 policy, drug structure index

Posted Date: November 30th, 2021

DOl: https://doi.org/10.21203/rs.3.rs-888080/v1

License: (9) (1) This work is licensed under a Creative Commons Attribution 4.0 International License. Read Full License 


\section{Abstract \\ Background}

In 2019, the Chinese government implemented the first round pilot of volume-based drug procurement in 4 municipalities and 7 sub-provincial cities, i.e. " $4+7$ " policy. This study evaluated the impact of " $4+7$ " policy on the use structure of policy-related drugs.

\section{Methods}

Data of China Drug Supply Information Platform (CDSIP) database was used, covering 18,636 public medical institutions from 9 pilot cities and 12 non-pilot provinces in mainland China. " $4+7$ " policy-related drugs were selected as study samples, including 25 drugs in the " $4+7$ " procurement List and 83 alternative drugs that have an alternative relationship with " $4+7$ " List drugs. " $4+7$ " List drugs were divided into bid-winning and bid-non-winning products. Drug Structure Index (DSI) was employed as the outcome variable, and higher DSI refers to the use proportion of higher-DDDc (Defined Daily Drug cost) drugs increased. Difference-in-difference (DID) method was employed to estimate the net effect of " $4+7$ " policy.

\section{Results}

After policy intervention, the DSI of bid-winning drugs significantly decreased $(\beta=-0.233, p<0.0001)$, while non-winning drugs $(\beta=0.177, p<0.001)$ and " $4+7$ " List drugs $(\beta=0.050, p<0.01)$ increased. No significant change was found for the overall DSI of alternative drugs $(\beta=0.013, p>0.05)$, while a remarkable increase was found in primary healthcare settings $(\beta=0.033, p<0.05)$. In three post-" $4+7$ " periods, the increments of DSI for non-winning products were $17.54 \%$ (period 1), $18.35 \%$ (period 2), and $19.66 \%$ (period 3 ). The DSI of " $4+7$ " List drugs significantly increased in post-" $4+7$ " period 2 and 3 (all $p$-values $<0.05$ ).

\section{Conclusions}

The use proportion of higher-DDDc bid-winning drugs significantly decreased after policy intervention. However, among drugs not involved by NCDP policy, the use proportion of higher-DDDc drugs significantly increased after policy intervention, moreover, the increment was more pronounced at the later periods of policy implementation. The clinical use monitoring and the physician's prescription behavior supervision should be strengthened.

\section{Introduction}

In China, the total pharmaceutical expenditure was 1914.90 billion yuan in 2018 , accounting for $32.73 \%$ of the total health expenditure [1], which was much higher than the average level of $17 \%$ in the Organization for Economic Co-operation and Development (OECD) countries [2]. The financial 
relationship between pharmaceutical companies and physicians' prescriptions is an important contributing factor to the continued growth of drug costs $[3,4]$. In China, medical institutions raised the supply of products and services with higher profits to make up for the decline in drug income [5]. Yip \& Hsiao [6] pointed out that although the medication markup has been abolished at the hospital level, some doctors in Chinese public hospitals still prescribe unnecessary drugs and get rebates from pharmaceutical enterprises. It is still a common phenomenon that medical institutions prefer to use highpriced drugs in China $[7,8]$.

In order to reduce the patients' burden of medication, cut off the gray interest chain between medical institutions/doctors and pharmaceutical enterprises, and purify the environment of the medical industry, in January 2019, the State Council of the People's Republic of China (PRC) issued the National Centralized Drug Procurement (NCDP) policy [9]. In the first round pilot of the NCDP policy, 4 municipalities (Beijing, Tianjin, Shanghai, and Chongqing) and 7 sub-provincial cities (Shenyang, Dalian, Xiamen, Guangzhou, Shenzhen, Chengdu, and Xi'an) in mainland China were selected as pilot cities, thus, this pilot is also known as " $4+7$ " policy. The highlight of " $4+7$ " policy lies in the implementation of "volume-based procurement", in which "Trade-for-price" and "Guarantee of use" were taken as the core policy measures [9]. As for the "Trade-for-price", each public medical institution in the pilot cities was required to submit the agreed procurement volume, and the National Healthcare Security Administration (NHSA) of the PRC organized competitive bidding and price negotiation based on the overall annual agreed procurement volume of 11 pilot cities. The pharmaceutical manufacturer with the lowest bid price in each drug won the bid. On December 17, 2018, the bid winning results were announced, and the average price reduction of 25 bid-winning products was 52\% [10]. As for the "Guarantee of use", eleven pilot cities were required to start implementing the NHSA's bid winning results before April 1, 2019. The purchases of all the bid-winning products were carried out on the provincial drug bidding and procurement platform. Besides, the use volume of each bid-winning product in each public medical institution in pilot cities was examined by NHSA to ensure the completion of the agreed procurement volume. Details of the NCDP policy elements were introduced in previous researches [11-13].

The implementation of NCDP policy has achieved remarkable results in improving the accessibility of policy-related drugs [14-16], promoting the substitution use of generic drugs [17], and increasing overall drug use quality level of the public [18]. However, several previous studies reported an upward trend in the consumption of policy-related drugs after the implementation of NCDP policy [11, 19], which should be concerned, especially for the incrased consumption of drugs have not been covered by NCDP policy. For drugs did not covered by volume-based procurement, the increase in usage might be explained that the gray interest chain between physicians and pharmaceutical enterprises still exists, and physicians still have the motivation to prescribe more medicines or choose higher-priced medicines [20]. Chen et al. [21] analyzed the impact of " $4+7$ " policy on drug use in Shenzhen using A.M. index method, and found that the structural effects of non-winning products and basic alternative drugs were 1.38 and 1.02 respectively (both greater than 1), indicating that the use proportion of drugs with higher daily costs increased after policy intervention. To further reveal the changes of drug use structure in China's public medical 
institutions under NCDP policy intervention, we conducted this exploratory study to quantitatively assess the impact of " $4+7$ " policy on the drug structure of " $4+7$ " policy-related drugs.

\section{Materials And Methods}

\subsection{Data sources}

Data used in this study was obtained from the China Drug Supply Information Platform (CDSIP) database. The CDSIP is a national drug database constructed and operated by the Statistical Information Center of the National Health Commission of the PRC, and was officially launched on October 22, 2015. Since then, health facilities upload information daily on ordering, storing and delivering, and medicines settlement to the CDSIP; the government can monitor prices, quantities, distribution and warehousing, and can organize medications purchased by medical institutions and strengthen management based on relevant information. Thus, the CDSIP database covered drug procurement order data of all provincial drug centralized procurement platforms from 31 provinces (autonomous regions and municipalities) in mainland China. Under the zero-markup drug policy in China [22], the drug purchase prices in public medical institutions are the same as the prices used by patients. Since 2015 , it was required that all drugs used by public medical institutions should be purchased through the provincial-level drug centralized procurement platform [23]. Therefore, in mainland China, the drug purchase data of public medical institutions in the CDSIP database is generally consistent with the drug use data.

In the CDSIP database, each drug purchase order record included the name of the medical institution, purchase date, drug YPID (Yao Pin Identifier) code, drug generic name, dosage form, specification, conversion factor, pharmaceutical manufacturer, price per unit, purchasing unit (by box, bottle, or branch), purchase volume, purchase expenditures, etc. Details of the CDSIP database are available elsewhere $[18,24]$. A total of 7,647 drugs (by generic name) and 141,624 products (by YPID code) were contained in this national database.

\subsection{Sample selection}

The inclusion criteria of study samples was as follows: (a) The drug scope was " $4+7$ " policy-related drugs, including 25 drugs (by generic name) in the " $4+7$ " List and the alternative drugs (supplementary table 1). The alternative drugs referred to drugs that had an alternative relationship with " $4+7$ " List drugs in clinical use, and was determined following the Monitoring Plan for the Pilot Work of National Centralized Drug Procurement and Use issued by the NHSA of the PRC [25]. The " $4+7$ " List drugs were then divided into bid-winning products and non-winning products according to the " $4+7$ " city centralized drug procurement bid-winning results announced by the Joint Procurement Office [10]. (b) The time period was 23 months from January 2018 to November 2019. (c) The scope of regions was pilot cities (i.e. pilot group) and non-pilot provinces (i.e. control group). The pilot group involved nine " $4+7$ " pilot cities, including Beijing, Shanghai, Chongqing, Tianjin, Chengdu, Xi'an, Shenyang, Dalian, and Xiamen. For two (Guangzhou and Shenzhen) of the eleven " $4+7$ " pilot cities that were not included in this study, their purchase order data in the CDSIP database was incomplete. The control group involved 12 provinces 
without the implementation of " $4+7$ " pilot policy, including Hubei, Hunan, Guizhou, Inner Mongolia, Jilin, Heilongjiang, Anhui, Hainan, Gansu, Qinghai, Ningxia, and Xinjiang. (d) The scope of health facilities were all the public medical institutions in the included 9 pilot cities and 12 non-pilot provinces, and were divided into tertiary hospitals, secondary hospitals, and primary healthcare centers (PHCs). Purchase order records with incomplete information were excluded.

Aggregated monthly drug procurement records of 4663 public medical institutions from 9 pilot cities and 13,973 public medical institutions from 12 non-pilot provinces were retrospectively analysed (Table 1). A total of 108 policy-related drugs (by generic name) were included in this study, including 25 " $4+7$ " List drugs and 83 alternative drugs. The flow chart of the sample selection process is shown in Figure 1.

\section{Table 1. Distribution of sample medical institutions.}

\begin{tabular}{|llll|}
\hline & Pilot group & Control group & Overall \\
\hline Tertiary & 356 & 613 & 969 \\
\hline Secondary & 488 & 1749 & 2237 \\
\hline Primary & 3819 & 11611 & 15430 \\
\hline Total & 4663 & 13973 & 18636 \\
\hline
\end{tabular}

\subsection{Outcome variables}

This study employed the Drug Structure Index (DSI) as the main outcome variable. In 2002, Antonio Addis and Nicola Magrini of the Italian Centre for Effectiveness Evaluation of Health Services constructed a method for analyzing the drug cost variance factors, known as A.M. index method [26]. This method divided drug cost changes into three parts: quantity factor, price factor, and structural factor, in which the structural factor represents the concept of "price structure" and refers to the combined structure of drugs at different prices. Based on the classical A.M. index system method, previous scholars constructed a drug structure index system, and has been applied in relevant studies $[27,28]$. The DSI represents the changes in the combination of drugs with different Defined Daily Drug cost (DDDc) in the same drug group, showing the transfer of use from drugs with lower (higher) prices to drugs with higher (lower) prices [29]. DSI is calculated as follows:

$$
D S I=\frac{\frac{\sum P_{1} Q_{1}}{\sum Q_{1}}}{\frac{\sum P_{1} Q_{0}}{\sum Q_{0}}}=\frac{\sum P_{1} Q_{1}}{\sum P_{0} Q_{0}} / \frac{\sum P_{1} Q_{0}}{\sum P_{0} Q_{0}} / \frac{\sum Q_{1}}{\sum Q_{0}}
$$


In formula (1), $Q$ represents the used quantity of drugs. The used quantity of each drug was measured based on its Defined Daily Dose (DDD), which is developed by WHO to compare drug consumptions and refers to the average maintenance dose per day for a drug used for its main indication in adults [30]. In this study, the DDD of the drugs which could not be coded in WHO's ATC/DDD Index 2021 system was determined based on the dosage regimen recommended in the manufacturers' instructions, as approved by China Food and Drug Administration. Prepresents the prices of drugs, which is expressed as DDDc. DDDc was calculated as drugs costs per unit DDD (DDDc=expenditures/DDDs).

The numbers of subscripts represent periods, with 0 representing the baseline period and 1 representing the reporting period. The higher the DSI, the higher the use proportion of drugs with higher DDDc in a "basket" of drugs. DSI>1 means that the use proportion of higher DDDc drugs increased in the reporting period compared with the baseline period; DSK 1 means that the use proportion of higher DDDc drugs decreased in the reporting period compared with the baseline period; $D S I=1$ means that the use proportion of higher DDDc drugs remains stable between reporting-period and baseline period.

This study observed the change of DSI in the pilot group and control group between the pre- and post-" $4+7$ " policy periods. In this study, January to March 2018 was assigned as the baseline period, and April 2018 to November 2019 was assigned as reporting periods, involving a total of 20 reporting periods. Finally, the time series of DSI for policy-related drugs were constructed containing 20 monthly time points.

\subsection{Statistical analysis}

Descriptive analysis was used to describe the distribution of DSI in the pilot group and control group, preand post-" $4+7$ " policy periods, different drug categories, and different levels of medical institutions. The line chart of DSI was drawn to describe the overall trend of drug structure changes from July 2018 to November 2019.

Difference-in-difference (DID) is a method commonly used for the quantitative effect evaluation of public policies or projects. By effectively combining "the difference before and after intervention" with "the difference with or without intervention", this method to a certain extent can control the influence of some factors other than intervention, so as to estimate the net impacts of the intervention on the outcome variable [31-33]. In order to eliminate the net effect of " $4+7$ " policy on the DSI change of policy-related drugs, we conducted DID models by using the DSI time series data in the pilot group and control group constructed above. The DID model is expressed as follows:

$$
Y=\beta_{0}+\beta_{1} T_{t}+\beta_{2} G_{t}+\beta_{3}\left(T_{t} * G_{t}\right)+\varepsilon_{t}
$$

In formula (2), $Y$ is the outcome variable, i.e. DSI in this study. $T_{t}$ refers to " $4+7$ " policy intervention with the value of 0 and 1, and 0 represents the pre-"4+7" policy period (from April 2018 to February 2019) and 1 represents the post-"4+7" policy period (from March 2019 to November 2019). G r $^{\text {represents groups }}$ 
with the value of 0 and 1 , and 0 represents the control group and 1 represents the pilot group. $\varepsilon_{t}$ is the error term, representing random errors that cannot be explained by variables in the model. $\beta_{0}$ represents the constant term. $\beta_{1}$ estimates the change of DSI in the post-" $4+7$ " policy period compared with the pre-" $4+7$ " policy period. $\beta_{2}$ estimates the change of DSI in the pilot group compared with the control group. $\beta_{3}$ represents DID value between the Pilot Group and the Control Group, is the DID value, which represents the interaction item between intervention measures and groups, that is, the net impacts of NCDP policy on DSI. The relative change of DSI after " $4+7$ " policy was expressed as $\beta_{3} / \beta_{0}$ [34]. In this study, we observed the monthly trends of outcome variable between pilot group and control group before the policy intervention, so as to verify if the DID model met the parallel trend conditions (supplementary figure 1) [35].

To further explore the change of DSI in different periods after the implementation of " $4+7$ " policy, this study divided the post-"4+7" policy period into three stages: Period 1 (March to May 2019), Period 2 (June to August 2019), and Period 3 (September to November 2019). The net impact of " $4+7$ " policy on the change of DSI was estimated in each of the three post-intervention periods compared with the pre-" $4+7$ " policy period. Stata version 16.0 was used to perform the analyses above. A $p$-value $<0.05$ was considered statistically significant.

\section{Results}

\subsection{Descriptive analysis results}

As shown in Table 2, in the pilot group, the DSI of bid-winning products declined from 1.05 to 0.74 with a decrease of $28.94 \%$ after the implementation of " $4+7$ " policy, while non-winning products increased from 1.05 to 1.29 with an increase of $22.92 \%$; the DSI of " $4+7$ " List drugs, alternative drugs, as well as the overall policy-related drugs increased by $6.41 \%, 7.21 \%$, and $5.21 \%$, respectively. In the control group, the DSI of bid-winning products dropped by $3.51 \%$, while non-winning products, " $4+7$ " List drugs, alternative drugs, and the overall policy-related drugs increased by $5.65 \%, 2.15 \%, 6.44 \%$, and $4.97 \%$, respectively.

Figure 2 presents the monthly trend of DSI of policy-related drugs in 9 pilot cities from April 2018 to November 2019. 
Table 2

Drug structure index of policy-related drugs in the pre- and post-" $4+7$ " policy periods.

\begin{tabular}{|c|c|c|c|c|c|c|}
\hline & \multicolumn{3}{|c|}{ Pilot Group } & \multicolumn{3}{|c|}{ Control Group } \\
\hline & Pre- & Post- & GR (\%) & Pre- & Post- & GR (\%) \\
\hline \multirow[t]{2}{*}{ Bid-winning drugs } & 1.05 & 0.74 & -28.94 & 1.01 & 0.98 & -3.51 \\
\hline & $\begin{array}{l}(0.99 \\
1.13)\end{array}$ & $\begin{array}{l}(0.72 \\
0.76)\end{array}$ & & $\begin{array}{l}(0.98 \\
1.05)\end{array}$ & $\begin{array}{l}(0.96 \\
1.02)\end{array}$ & \\
\hline \multirow[t]{2}{*}{ Non-winning drugs } & 1.05 & 1.29 & 22.92 & 0.99 & 1.05 & 5.65 \\
\hline & $\begin{array}{l}(1.02 \\
1.07)\end{array}$ & $\begin{array}{l}(1.23, \\
1.34)\end{array}$ & & $\begin{array}{l}(0.96, \\
1.03)\end{array}$ & $\begin{array}{l}(1.00 \\
1.09)\end{array}$ & \\
\hline \multirow[t]{2}{*}{ "4+7" List drugs } & 1.05 & 1.12 & 6.41 & 1.01 & 1.03 & 2.15 \\
\hline & $\begin{array}{l}(1.02, \\
1.07)\end{array}$ & $\begin{array}{l}(1.07 \\
1.15)\end{array}$ & & $\begin{array}{l}(0.98, \\
1.05)\end{array}$ & $\begin{array}{l}(0.99 \\
1.07)\end{array}$ & \\
\hline \multirow[t]{2}{*}{ Alternative drugs } & 1.00 & 1.07 & 7.21 & 0.99 & 1.06 & 6.44 \\
\hline & $\begin{array}{l}(0.96 \\
1.07)\end{array}$ & $\begin{array}{l}(1.03, \\
1.09)\end{array}$ & & $\begin{array}{l}(0.94 \\
1.12)\end{array}$ & $\begin{array}{l}(1.02, \\
1.10)\end{array}$ & \\
\hline \multirow{2}{*}{$\begin{array}{l}\text { Overall policy-related } \\
\text { drugs }\end{array}$} & 1.03 & 1.08 & 5.21 & 1.01 & 1.06 & 4.97 \\
\hline & $\begin{array}{l}(1.00 \\
1.07)\end{array}$ & $\begin{array}{l}(1.04, \\
1.11)\end{array}$ & & $\begin{array}{l}\text { (0.97, } \\
1.07)\end{array}$ & $\begin{array}{l}(1.00, \\
1.10)\end{array}$ & \\
\hline
\end{tabular}

Table 3 demonstrates the change of DSI in different levels of public medical institutions. In the pilot group, the DSI of bid-winning products decreased by $28.89 \%, 25.78 \%$, and $25.24 \%$ in tertiary hospitals, secondary hospitals, and PHCs respectively, while non-winning products increased by $16.47 \%, 20.55 \%$, and $14.88 \%$ respectively. The DSI of alternative drugs rose by $11.72 \%, 2.83 \%$, and $3.88 \%$ in tertiary hospitals, secondary hospitals, and PHCs respectively. 
Table 3

Drug structure index of policy-related drugs in different healthcare settings in the pre- and post-" $4+7$ " periods.

\begin{tabular}{|c|c|c|c|c|c|c|}
\hline & \multicolumn{3}{|c|}{ Pilot Group } & \multicolumn{3}{|c|}{ Control Group } \\
\hline & Pre- & Post- & GR (\%) & Pre- & Post- & GR (\%) \\
\hline \multicolumn{7}{|l|}{ Bid-winning drugs } \\
\hline \multirow[t]{2}{*}{ Tertiary hospitals } & 1.05 & 0.75 & -28.89 & 1.02 & 0.99 & -2.98 \\
\hline & $\begin{array}{l}(0.99 \\
1.16)\end{array}$ & $\begin{array}{l}(0.70 \\
0.78)\end{array}$ & & $\begin{array}{l}(0.99 \\
1.07)\end{array}$ & $\begin{array}{l}(0.96 \\
1.04)\end{array}$ & \\
\hline \multirow[t]{2}{*}{ Secondary hospitals } & 1.00 & 0.75 & -25.78 & 1.02 & 1.00 & -1.68 \\
\hline & $\begin{array}{l}(0.98 \\
1.04)\end{array}$ & $\begin{array}{l}(0.72 \\
0.77)\end{array}$ & & $\begin{array}{l}(0.97 \\
1.12)\end{array}$ & $\begin{array}{l}(0.95 \\
1.05)\end{array}$ & \\
\hline \multirow[t]{2}{*}{ PHCs } & 1.06 & 0.79 & -25.24 & 1.06 & 1.01 & -4.15 \\
\hline & $\begin{array}{l}(1.00 \\
1.10)\end{array}$ & $\begin{array}{l}(0.77 \\
0.81)\end{array}$ & & $\begin{array}{l}(0.99 \\
1.14)\end{array}$ & $\begin{array}{l}(0.98 \\
1.08)\end{array}$ & \\
\hline \multicolumn{7}{|l|}{ Non-winning drugs } \\
\hline \multirow[t]{2}{*}{ Tertiary hospitals } & 1.05 & 1.22 & 16.47 & 0.96 & 0.99 & 2.33 \\
\hline & $\begin{array}{l}(1.02, \\
1.07)\end{array}$ & $\begin{array}{l}(1.17 \\
1.26)\end{array}$ & & $\begin{array}{l}(0.92 \\
1.00)\end{array}$ & $\begin{array}{l}(0.96 \\
1.01)\end{array}$ & \\
\hline \multirow[t]{2}{*}{ Secondary hospitals } & 1.04 & 1.25 & 20.55 & 1.03 & 1.08 & 4.64 \\
\hline & $\begin{array}{l}(1.01 \\
1.07)\end{array}$ & $\begin{array}{l}(1.16 \\
1.35)\end{array}$ & & $\begin{array}{l}(1.01 \\
1.05)\end{array}$ & $\begin{array}{l}(1.02, \\
1.11)\end{array}$ & \\
\hline \multirow[t]{2}{*}{ PHCs } & 1.05 & 1.21 & 14.88 & 1.07 & 1.27 & 18.90 \\
\hline & $\begin{array}{l}(1.01 \\
1.08)\end{array}$ & $\begin{array}{l}(1.12, \\
1.31)\end{array}$ & & $\begin{array}{l}(0.93 \\
1.17)\end{array}$ & $\begin{array}{l}(1.18 \\
1.39)\end{array}$ & \\
\hline \multicolumn{7}{|l|}{ "4+7" List drugs } \\
\hline \multirow[t]{2}{*}{ Tertiary hospitals } & 1.05 & 1.08 & 2.70 & 1.04 & 1.04 & 0.84 \\
\hline & $\begin{array}{l}(1.02 \\
1.10)\end{array}$ & $\begin{array}{l}(1.04 \\
1.13)\end{array}$ & & $\begin{array}{l}(0.99 \\
1.09)^{\prime}\end{array}$ & $\begin{array}{l}(1.01 \\
1.07)\end{array}$ & \\
\hline \multirow[t]{2}{*}{ Secondary hospitals } & 1.04 & 1.09 & 5.57 & 1.02 & 1.05 & 3.50 \\
\hline & $\begin{array}{l}(1.01 \\
1.06)\end{array}$ & $\begin{array}{l}(1.04, \\
1.14)\end{array}$ & & $\begin{array}{l}(0.99 \\
1.06)\end{array}$ & $\begin{array}{l}(1.00, \\
1.08)\end{array}$ & \\
\hline
\end{tabular}

Note: Data are mean (min, max). Pre- refers to April 2018 to February 2019; Post- refers to March to November 2019. GR, growth rate. PHCs, primary healthcare centers. 


\begin{tabular}{|c|c|c|c|c|c|c|}
\hline \multirow[b]{2}{*}{ PHCs } & \multicolumn{3}{|c|}{ Pilot Group } & \multicolumn{3}{|c|}{ Control Group } \\
\hline & 1.05 & 1.11 & 5.81 & 1.03 & 1.10 & 6.61 \\
\hline & $\begin{array}{l}(1.01 \\
1.08)\end{array}$ & $\begin{array}{l}(1.02 \\
1.16)\end{array}$ & & $\begin{array}{l}(0.98 \\
1.09)\end{array}$ & $\begin{array}{l}(1.05 \\
1.15)\end{array}$ & \\
\hline \multicolumn{7}{|l|}{ Alternative drugs } \\
\hline \multirow[t]{2}{*}{ Tertiary hospitals } & 1.01 & 1.13 & 11.72 & 0.99 & 1.07 & 8.24 \\
\hline & $\begin{array}{l}(0.97 \\
1.10)\end{array}$ & $\begin{array}{l}(1.03 \\
1.18)\end{array}$ & & $\begin{array}{l}(0.95 \\
1.07)\end{array}$ & $\begin{array}{l}(1.05 \\
1.12)\end{array}$ & \\
\hline \multirow[t]{2}{*}{ Secondary hospitals } & 0.99 & 1.01 & 2.83 & 0.98 & 1.02 & 4.18 \\
\hline & $\begin{array}{l}(0.95 \\
1.06)\end{array}$ & $\begin{array}{l}(1.00 \\
1.03)\end{array}$ & & $\begin{array}{l}(0.94 \\
1.04)\end{array}$ & $\begin{array}{l}(0.99 \\
1.05)\end{array}$ & \\
\hline \multirow[t]{2}{*}{ PHCs } & 0.99 & 1.03 & 3.88 & 1.01 & 1.02 & 0.61 \\
\hline & $\begin{array}{l}(0.97 \\
1.03)\end{array}$ & $\begin{array}{l}(1.00 \\
1.04)\end{array}$ & & $\begin{array}{l}(0.97 \\
1.06)\end{array}$ & $\begin{array}{l}(0.99 \\
1.04)\end{array}$ & \\
\hline \multicolumn{7}{|l|}{$\begin{array}{l}\text { Overall policy-related } \\
\text { drugs }\end{array}$} \\
\hline \multirow[t]{2}{*}{ Tertiary hospitals } & 1.04 & 1.11 & 6.21 & 1.02 & 1.07 & 4.95 \\
\hline & $\begin{array}{l}(1.01 \\
1.09)\end{array}$ & $\begin{array}{l}(1.05 \\
1.15)\end{array}$ & & $\begin{array}{l}(0.98 \\
1.06)\end{array}$ & $\begin{array}{l}(1.03 \\
1.11)\end{array}$ & \\
\hline \multirow[t]{2}{*}{ Secondary hospitals } & 1.01 & 1.03 & 1.63 & 1.02 & 1.09 & 6.57 \\
\hline & $\begin{array}{l}(0.99 \\
1.05)\end{array}$ & $\begin{array}{l}(0.99 \\
1.05)\end{array}$ & & $\begin{array}{l}(1.00 \\
1.09)\end{array}$ & $\begin{array}{l}(1.04 \\
1.13)\end{array}$ & \\
\hline \multirow[t]{2}{*}{ PHCs } & 1.03 & 1.06 & 2.87 & 1.03 & 1.08 & 4.54 \\
\hline & $\begin{array}{l}(1.00 \\
1.05)\end{array}$ & $\begin{array}{l}(1.00 \\
1.07)\end{array}$ & & $\begin{array}{l}(0.97 \\
1.11)\end{array}$ & $\begin{array}{l}(1.05, \\
1.11)\end{array}$ & \\
\hline
\end{tabular}

\subsection{DID analysis results}

Table 4 summarizes the results of DID analysis for the DSI of policy-related drugs in different healthcare settings. The DSI of bid-winning products decreased significantly $(\beta=-0.233, p<0.0001)$, among which significant decreases were observed in tertiary hospitals $(\beta=-0.239, p<0.0001)$, secondary hospitals $(\beta=$ $-0.205, p<0.0001)$, and PHCs $(\beta=-0.207, p<0.0001)$. The DSI of non-winning products decreased significantly in all medical institutions $(\beta=0.177, p<0.0001)$. A significant increase in the DSI of non- 
winning products was observed in the healthcare settings of tertiary $(\beta=0.147, p<0.0001)$ and secondary hospitals $(\beta=0.162, p<0.0001)$, while no significant change was found in PHCs $(\beta=-0.042, p>0.05)$. 
Table 4

Difference-in-difference analysis for the change of drug structure index of policy-related drugs in different healthcare settings.

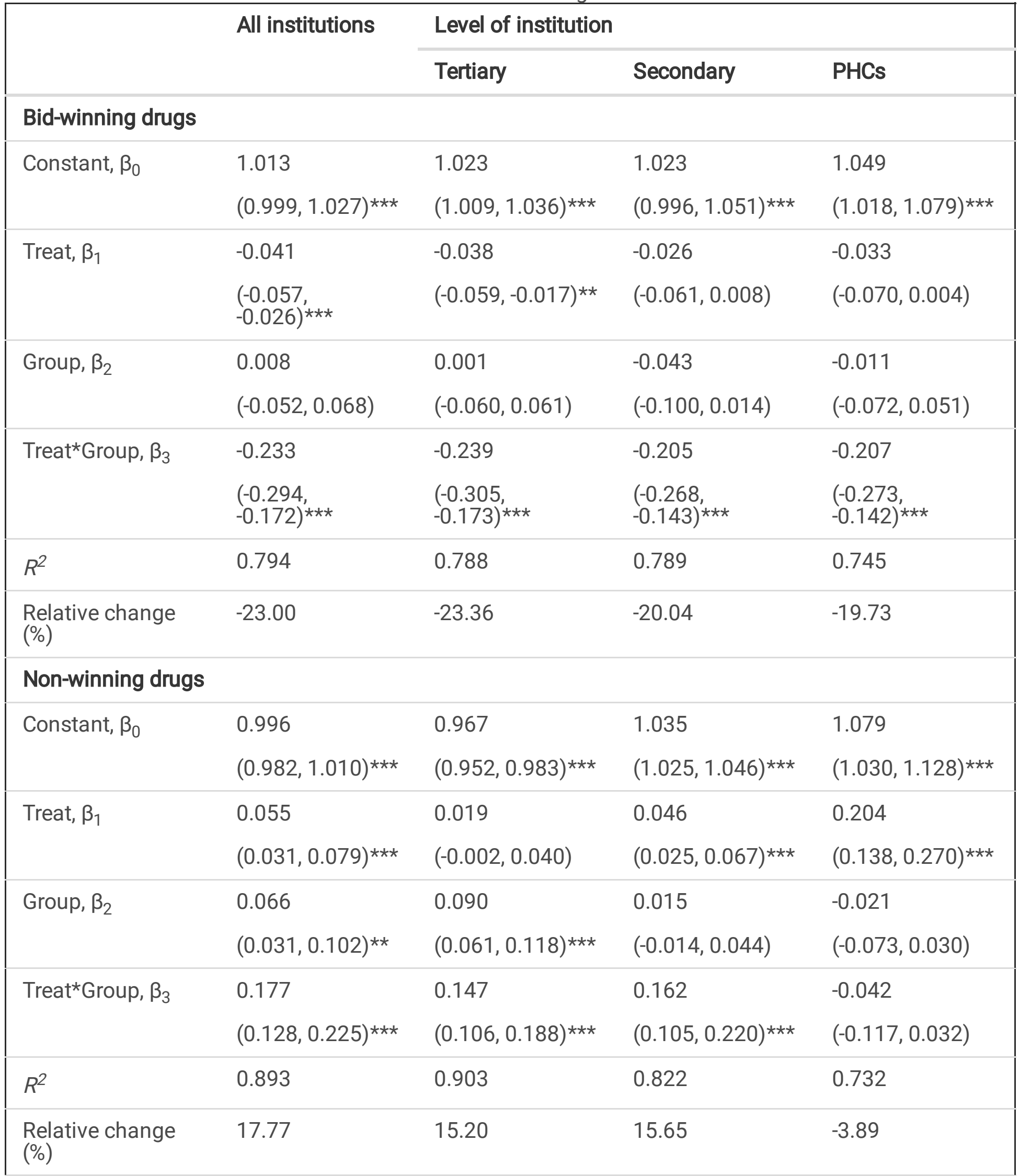

Note: ${ }^{* \star \star} p$-value $<0.001,{ }^{* \star} p$-value $<0.01,{ }^{*} p$-value $<0.05$. PHCs, primary healthcare centers. 


\begin{tabular}{|c|c|c|c|c|}
\hline \multirow{3}{*}{ "4+7" List drugs } & \multirow[t]{2}{*}{ All institutions } & \multicolumn{3}{|l|}{ Level of institution } \\
\hline & & \multirow[t]{2}{*}{ Tertiary } & \multirow[t]{2}{*}{ Secondary } & \multirow[t]{2}{*}{ PHCs } \\
\hline & & & & \\
\hline \multirow[t]{2}{*}{ Constant, $\beta_{0}$} & 1.012 & 1.036 & 1.019 & 1.032 \\
\hline & $(0.999,1.026)^{\star \star \star}$ & $(1.021,1.051)^{\star \star \star}$ & $(1.006,1.032)^{\star \star \star}$ & $(1.010,1.054)^{\star \star \star}$ \\
\hline \multirow[t]{2}{*}{ Treat, $\beta_{1}$} & 0.022 & 0.008 & 0.032 & 0.072 \\
\hline & $(-0.004,0.048)$ & $(-0.015,0.030)$ & $(0.008,0.056) \star \star$ & $(0.039,0.104)^{\star \star \star}$ \\
\hline \multirow[t]{2}{*}{ Group, $\beta_{2}$} & 0.038 & 0.017 & 0.016 & 0.015 \\
\hline & $(0.021,0.055)^{\star \star \star}$ & $(-0.003,0.038)$ & $(0.001,0.032) *$ & $(-0.011,0.041)$ \\
\hline \multirow[t]{2}{*}{ Treat*Group, $\beta_{3}$} & 0.050 & 0.027 & 0.032 & 0.004 \\
\hline & $(0.019,0.081)^{\star \star}$ & $(-0.006,0.060)$ & $(-0.001,0.066)$ & $(-0.035,0.042)$ \\
\hline$R^{2}$ & 0.766 & 0.390 & 0.621 & 0.624 \\
\hline $\begin{array}{l}\text { Relative change } \\
(\%)\end{array}$ & 4.94 & 2.61 & 3.14 & 0.39 \\
\hline \multicolumn{5}{|l|}{ Alternative drugs } \\
\hline \multirow[t]{2}{*}{ Constant, $\beta_{0}$} & 0.997 & 0.994 & 0.985 & 1.010 \\
\hline & $(0.967,1.027)^{\star \star \star}$ & $(0.971,1.017)^{\star \star \star}$ & $(0.968,1.002)^{\star \star \star}$ & $(0.990,1.030)^{\star \star \star}$ \\
\hline \multirow[t]{2}{*}{ Treat, $\beta_{1}$} & 0.061 & 0.079 & 0.035 & 0.008 \\
\hline & $(0.026,0.095)^{\star \star}$ & $(0.052,0.107)^{\star \star \star}$ & $(0.014,0.057)^{\star \star}$ & $(-0.015,0.031)$ \\
\hline \multirow[t]{2}{*}{ Group, $\beta_{2}$} & 0.005 & 0.025 & 0.002 & -0.020 \\
\hline & $(-0.031,0.042)$ & $(-0.010,0.060)$ & $(-0.024,0.029)$ & $(-0.044,0.003)$ \\
\hline \multirow[t]{2}{*}{ Treat ${ }^{\star}$ Group, $\beta_{3}$} & 0.013 & 0.044 & -0.008 & 0.033 \\
\hline & $(-0.029,0.056)$ & $(-0.007,0.095)$ & $(-0.038,0.022)$ & $(0.005,0.060)^{\star}$ \\
\hline$R^{2}$ & 0.478 & 0.673 & 0.283 & 0.296 \\
\hline $\begin{array}{l}\text { Relative change } \\
(\%)\end{array}$ & 1.30 & 4.43 & -0.81 & 3.27 \\
\hline $\begin{array}{l}\text { Overall policy- } \\
\text { related drugs }\end{array}$ & & & & \\
\hline
\end{tabular}

Note: ${ }^{\star \star \star} p$-value $<0.001,{ }^{* \star} p$-value $<0.01,{ }^{*} p$-value $<0.05$. PHCs, primary healthcare centers. 


\begin{tabular}{|c|c|c|c|c|}
\hline & \multirow[t]{2}{*}{ All institutions } & \multicolumn{3}{|l|}{ Level of institution } \\
\hline & & Tertiary & Secondary & PHCs \\
\hline \multirow[t]{2}{*}{ Constant, $\beta_{0}$} & 1.015 & 1.022 & 1.024 & 1.032 \\
\hline & $(0.994,1.036)^{\star \star \star}$ & $(1.007,1.038)^{\star \star \star}$ & $(1.005,1.043)^{\star \star \star}$ & $(1.011,1.054)^{\star \star \star}$ \\
\hline \multirow[t]{2}{*}{ Treat, $\beta_{1}$} & 0.049 & 0.048 & 0.062 & 0.048 \\
\hline & $(0.016,0.081)^{\star \star}$ & $(0.023,0.072)^{\star \star \star}$ & $(0.033,0.090)^{\star \star \star}$ & $(0.021,0.074)^{\star \star}$ \\
\hline \multirow[t]{2}{*}{ Group, $\beta_{2}$} & 0.017 & 0.020 & -0.011 & -0.009 \\
\hline & $(-0.007,0.040)$ & $(-0.003,0.042)$ & $(-0.033,0.011)$ & $(-0.033,0.014)$ \\
\hline \multirow[t]{2}{*}{ Treat*Group, $\beta_{3}$} & 0.010 & 0.023 & -0.039 & -0.008 \\
\hline & $(-0.025,0.045)$ & $(-0.012,0.057)$ & $(-0.071,-0.006)^{\star}$ & $(-0.037,0.020)$ \\
\hline$R^{2}$ & 0.544 & 0.628 & 0.547 & 0.486 \\
\hline $\begin{array}{l}\text { Relative change } \\
(\%)\end{array}$ & 0.99 & 2.25 & -3.81 & -0.78 \\
\hline
\end{tabular}

The DSI of " $4+7$ " List drugs significantly increased $(\beta=0.050, p<0.01)$. No statistical significance was observed for the change of DSI for alternative drugs $(\beta=0.013, p>0.05)$, while a remarkable increase was found in the DSI of " $4+7$ " List drugs in PHCs $(\beta=0.033, p<0.05)$. The DSI of overall policy-related drugs showed no statistical difference after the implementation of " $4+7$ " policy $(\beta=0.010, p>0.05)$, while the DSI of overall policy-related drugs in the secondary hospitals showed a notable decrease $(\beta=-0.039, p$ $<0.05)$.

\subsection{Subgroup analysis for different post-intervention periods}

Table 5 shows the DID analysis for the change of DSI of policy-related drugs in different post-" $4+7$ " policy periods. The DSI of bid-winning products substantially decreased in Period $1(\beta=-0.288, p<0.001)$, Period $2(\beta=-0.264, p<0.001)$, and Period $3(\beta=-0.252, p<0.001)$, and the relative change in three periods showed a downward trend $(-28.43 \%,-26.06 \%$, and $-24.88 \%)$. The DSI of non-winning products significantly increased in Period $1(\beta=0.174, p<0.001)$, Period $2(\beta=0.182, p<0.001)$ and Period $3(\beta=$ $0.195, p<0.001)$, and the relative change in three periods showed an upward trend $(17.54 \%, 18.35 \%$, and $19.66 \%)$. 
Table 5

Difference-in-difference analysis for the change of drug structure index of policy-related drugs in different post-" $4+7 "$ policy periods.

\section{Period 1 \\ Period 2 \\ Period 3}

\section{Bid-winning drugs}

Constant, $\beta_{0}$

Treat, $\beta_{1}$

Group, $\beta_{2}$

Treat*Group, $\beta_{3}$

$R^{2}$

Relative change $\quad-28.43$

(\%) $1.013(0.997,1.029)^{\star \star \star}$

$-0.027(-0.062,0.008)$

$0.035(0.007,0.063)$ *

$-0.288(-0.333$,

$-0.242)^{\star \star \star}$

0.917 $1.013(0.997,1.029)^{\star \star \star}$

$-0.038(-0.060,-0.015)^{\star \star}$

$0.035(0.007,0.063)^{\star}$

$-0.264(-0.300$,

$-0.227)^{\star \star \star}$

0.915

$-26.06$ $1.013(0.997,1.029)^{\star \star \star}$

$-0.042(-0.061$, $-0.023)^{\star \star \star}$

$0.035(0.007,0.063)$ *

$-0.252(-0.282$,

$-0.221)^{\star \star \star}$

0.914

$-24.88$

\section{Non-winning drugs}

\begin{tabular}{llll}
\hline Constant, $\beta_{0}$ & $0.992(0.979,1.006) \star \star \star$ & $0.992(0.979,1.006)^{\star \star \star}$ & $0.992(0.979,1.006)^{\star \star \star}$ \\
\hline Treat, $\beta_{1}$ & $0.042(0.022,0.061)^{\star \star \star}$ & $0.075(0.059,0.091)^{\star \star \star}$ & $0.051(0.006,0.097)^{\star}$ \\
\hline Group, $\beta_{2}$ & $0.054(0.037,0.072)^{\star \star \star}$ & $0.054(0.037,0.072)^{\star \star \star}$ & $0.054(0.037,0.072)^{\star \star \star}$ \\
\hline Treat*Group, $\beta_{3}$ & $0.174(0.138,0.211)^{\star \star \star}$ & $0.182(0.134,0.230)^{\star \star \star}$ & $0.195(0.124,0.267)^{\star \star \star}$ \\
\hline$R^{2}$ & 0.948 & 0.954 & 0.929 \\
\hline $\begin{array}{l}\text { Relative change } \\
(\%)\end{array}$ & 17.54 & 18.35 & 19.66 \\
\hline
\end{tabular}

\section{" $4+7$ " List drugs}

\begin{tabular}{llll} 
Constant, $\beta_{0}$ & $1.011(0.996,1.027) \star \star \star$ & $1.011(0.996,1.027)^{\star \star \star}$ & $1.011(0.996,1.027)^{\star \star \star}$ \\
\hline Treat, $\beta_{1}$ & $0.008(-0.015,0.032)$ & $0.044(0.022,0.066)^{\star \star \star}$ & $0.013(-0.035,0.061)$ \\
\hline Group, $\beta_{2}$ & $0.038(0.019,0.057)^{\star \star \star}$ & $0.038(0.019,0.057)^{\star \star \star}$ & $0.038(0.019,0.057)^{\star \star \star}$ \\
\hline Treat*Group, $\beta_{3}$ & $0.039(-0.004,0.083)$ & $0.043(0.012,0.074)^{\star \star}$ & $0.054(0.003,0.106)^{\star}$ \\
\hline$R^{2}$ & 0.639 & 0.794 & 0.685 \\
\hline $\begin{array}{l}\text { Relative change } \\
(\%)\end{array}$ & 3.86 & 4.25 & 5.34 \\
\hline
\end{tabular}

Note: ${ }^{* *} p$-value $<0.001,{ }^{* *} p$-value $<0.01,{ }^{*} p$-value $<0.05$. 


\section{Period 1}

Period 2

Period 3

\section{Alternative drugs}

\begin{tabular}{llll} 
Constant, $\beta_{0}$ & $0.993(0.960,1.025)^{\star \star *}$ & $0.993(0.960,1.025)^{\star \star *}$ & $0.993(0.960,1.025)^{\star \star \star}$ \\
\hline Treat, $\beta_{1}$ & $0.055(0.022,0.088) \star *$ & $0.087(0.050,0.124)^{\star \star \star}$ & $0.050(0.007,0.093)^{\star}$ \\
\hline Group, $\beta_{2}$ & $0.007(-0.033,0.047)$ & $0.007(-0.033,0.047)$ & $0.007(-0.033,0.047)$ \\
\hline Treat*Group, $\beta_{3}$ & $0.011(-0.039,0.061)$ & $-0.016(-0.072,0.039)$ & $0.030(-0.020,0.079)$ \\
\hline$R^{2}$ & 0.309 & 0.419 & 0.357 \\
$\begin{array}{l}\text { Relative change } \\
(\%)\end{array}$ & 1.11 & -1.61 & 3.02
\end{tabular}

\section{Overall policy-}

related drugs

\begin{tabular}{llll} 
Constant, $\beta_{0}$ & $1.012(0.989,1.035) \star \star \star$ & $1.012(0.989,1.035)^{\star \star \star}$ & $1.012(0.989,1.035)^{\star \star \star}$ \\
\hline Treat, $\beta_{1}$ & $0.038(0.013,0.062)^{\star \star}$ & $0.077(0.050,0.104)^{\star \star \star}$ & $0.036(-0.020,0.093)$ \\
\hline Group, $\beta_{2}$ & $0.019(-0.007,0.045)$ & $0.019(-0.007,0.045)$ & $0.019(-0.007,0.045)$ \\
\hline Treat*Group, $\beta_{3}$ & $0.003(-0.039,0.046)$ & $-0.013(-0.047,0.021)$ & $0.020(-0.038,0.078)$ \\
\hline$R^{2}$ & 0.355 & 0.596 & 0.404 \\
\hline $\begin{array}{l}\text { Relative change } \\
(\%)\end{array}$ & 0.30 & -1.28 & 1.98
\end{tabular}

Note: ${ }^{\star \star \star} p$-value $<0.001,{ }^{* \star} p$-value $<0.01,{ }^{\star} p$-value $<0.05$

For " $4+7$ " List drugs, The DSI did not change significantly in Period $1(\beta=0.039, p>0.05)$, while significantly increased in Period $2(\beta=0.043, p<0.01)$ and Period $3(\beta=0.054, p<0.05)$. In terms of the alternative drugs and the overall policy-related drugs, no statistical significance was observed in the change of DSI at all three periods (all $p$-values $>0.05$ ). In addition, the DID analysis of different levels of medical institutions at different post-intervention periods showed (supplementary table 2 ) that the DSI of alternative drugs increased significantly in tertiary hospitals $(\beta=0.075, p<0.01)$ and PHCs $(\beta=0.032, p$ $<0.05)$ in post-" $4+7$ " policy period 3.

\section{Discussion}


This study analyzed the changes in DSI of policy-related drugs before and after " $4+7$ " policy. After the implementation of " $4+7$ " policy, the use proportion of higher DDDc drugs in the bid-winning products decreased significantly. Significant increases were observed in the DSI of non-winning products in the healthcare settings of secondary and tertiary hospitals, and the DSI of alternative drugs in PHCs. This study also found that the increment of DSI showed an increasing trend in the three post-" $4+7$ " periods.

In this study, we found that the DSI of bid-winning products dropped significantly, that is, " $4+7$ " policy directly promoted the substitution use of lower DDDc drugs on higher DDDc drugs. This effect is mainly attributed to the NCDP policy element of "guaranteed use" [36, 9]. The NHSA monitored and assessed the clinical use of bid-winning drugs in each public medical institution in pilot cities, which greatly promoted the increasing use of drugs with lower daily costs. In addition, compared with the bid-winning prices of each drug, it can be seen that the lower-DDDc drugs among " $4+7$ " bid-winning products are mainly cardiovascular system drugs [10]. It indicated that " $4+7$ " policy played positive roles in ensuring the medication of patients with chronic diseases. Besides, it is worth mentioning that a slight decline was also observed in non-pilot areas (control group) for the DSI of bid-winning products, reflecting a certain cross-regional positive effect of " $4+7$ " policy.

This study found a prominent rise in DSI for non-winning products after the implementation of " $4+7$ " policy, that is, the proportion of higher DDDc drugs among non-winning products increased. On the one hand, this situation may stem from reasonable clinical demands that patients still have a greater use demand for the original branded drugs in the non-winning products. For example, He et al. [37] surveyed five " $4+7$ " pilot cities and found that some prescribing physicians and patients believed the quality gap between bid-winning generic drugs and original branded drugs, and therefore tended to insist on using non-winning original branded drugs; Qu et al. [17] also mentioned that pharmacists in China still have concerns regarding the reliability and quality of generic drugs. On the other hand, China's public medical institutions lack the motivation to actively reduce the use of high-priced drugs $[7,8]$, thus the increased DSI for non-winning products in this study may be related to the change of physicians' prescription behavior induced by enterprise sales behavior [20]. In addition, we also found that the increase in DSI of non-winning products was mainly reflected in the healthcare settings of tertiary and secondary hospitals, suggesting that it is necessary to strengthen the monitoring and supervision of prescriptions for " $4+7$ " List drugs in these hospitals in the future.

In this study, we analyzed the change of DSI for the drugs that have an alternative relationship with " $4+7$ " List drugs in clinical use, and no significant change was found in tertiary and secondary hospitals, while a prominent increase in DSI for alternative drugs was observed in primary healthcare settings. Previous studies found that, after the implementation of NCDP policy, the use volume and costs of the alternative drugs significantly increased [21, 11], which has weakened the cost-saving effect of the policy to a certain extent. Neither the increase in the overall use volume and cost of alternative drugs, nor the increase in the use proportion of higher DDDc drugs among alternative medicines, is what policymakers want to see. To some extent, these phenomena might be related to physicians' attempts to obtain benefits by prescribing non-centralized purchased drugs [20]. The finding of this study indicated that, under NCDP policy, the 
clinical use monitoring should focus not only on " $4+7$ " List drugs, but also drugs that have an alternative relationship with " $4+7$ " List drugs in clinical use. And drug use monitoring regarding policy-related drugs in primary healthcare settings might be particularly important.

This study found that, compared with the pre-"4+7" policy period, the DSI changes of policy-related drugs in different post-" $4+7$ " periods were quite different. In the three post-" $4+7$ " periods, the DSI of non-winning products increased significantly compared to the pre-" $4+7$ " policy period, with the relative changes increasing by $17.54 \%$ (post-intervention period 1), $18.35 \%$ (post-intervention period 2 ), and $19.66 \%$ (postintervention period 3), respectively, as the policy progressed. The analysis of " $4+7$ " List drugs in different post-intervention periods should that the DSI did not change significantly in the post-intervention period 1 , while increased significantly in the post-intervention period 2 and 3, with relative changes of $4.25 \%$ (period 2) and 5.35\% (period 3). It can be seen that, with the progress of NCDP policy, the use proportion of higher DDDc drugs among policy-related drugs was increasing, mainly reflected in non-winning products. This may be related to the physicians' prescription switching after the use target of bid-winning products has been completed at the later periods of policy implementation. Therefore, it is recommended to strengthen the whole-process drug use monitoring in the NCDP policy implementation process, and to reduce unnecessary prescription conversion of patients.

Several potential limitations should be reported regarding the present study. First, " $4+7$ " policy was implemented in 11 pilot cities, while this study only included 9 pilot cities for analysis due to the incomplete data of two pilot cities (Guangzhou and Shenzhen) in the CDSIP database. This study used data from January 2018 to November 2019, while the policy implementation was less than one complete procurement cycle during this period. Thus, in terms of the sample cities and the study periods, this study failed to conduct a comprehensive assessment of the final effect of the policy. Second, the results of this study were based on drug purchase data, rather than drug use data (such as prescriptions). Although there is strong consistency between purchase data and use data under a series of policies. However, there is still a possibility that the two data sources may not exactly match, so there are certain limitations.

\section{Conclusion}

This study assessed the impact of " $4+7$ " policy on the DSI of policy-related drugs. A satisfying effect was observed that the use proportion of higher DDDc drugs in the bid-winning products decreased significantly. However, we found significant increases in the use proportion of higher DDDc drugs among non-winning products and alternative drugs after the implementation of " $4+7$ " policy. Moreover, the increase in the use proportion of higher DDDc drugs was more pronounced at the later periods of policy implementation. Thus, it is necessary to strengthen the clinical use monitoring and the physicians' prescription behavior supervision under NCDP policy, and the monitoring should focus not only on " $4+7$ " List drugs, but also on drugs that have an alternative relationship with " $4+7$ " List drugs in clinical use. Moreover, the clinical use monitoring of NCDP policy-related drugs should be strictly executed in the whole policy implementation process, and to reduce the unnecessary prescription conversion of patients during the policy implementation cycle. 


\section{Abbreviations}

OECD: Organization for Economic Co-operation and Development; PRC: People's Republic of China; NCDP: National Centralized Drug Procurement; NHSA: National Healthcare Security Administration; CDSIP: China Drug Supply Information Platform; YPID: Yao Pin Identifier; PHCs: Primary Healthcare Centers; DSI: Drug Structure Index; DDDc: Defined Daily Drug cost; DDDs: Defined Daily Doses; DID: Difference-in-difference.

\section{Declarations}

\section{Ethics approval and consent to participate}

This study was conducted in accordance with the Declaration of Helsinki. The study protocol was reviewed and approved by the Institutional Review Board of Wuhan University. In this research, we only included the medication procurement information and all the information was anonymous. Neither patients nor the public were involved in this research. Thus, according to the Institutional Review Board of Wuhan University, the requirement for patient consent was waived.

\section{Consent for publication}

Not applicable

\section{Availability of data and materials}

The data used in this study is not publicly available. The dataset (CDSIP database) used and analyzed during the current study is available from the corresponding author on reasonable request. In this study, no additional data is used.

\section{Competing interests}

The authors declare no conflict of interest.

\section{Funding}

This study was funded by the project of National-level Key Research and Development Plan in 13th FiveYear Plan (grant number: 2018YFC2000302). The funders had no role in study design, data collection and analysis, decision to publish, or preparation of the manuscript.

\section{Authors' contributions}

Conceptualization, JCL, DC, and JHL; methodology, YY and DC; software, YY and HFL; validation, JCL, $\mathrm{DC}$, and JHL; formal analysis, YY; investigation, HFL, JW and YS; resources, JCL, JW and YS; data curation, JCL, JW, and YS; writing-original draft preparation, JCL, YY, HFL, and DC; writing-review and editing, JCL, YY, ZFM, JHL; visualization, YY and HFL; supervision, ZFM, DC, JHL; project administration, 
ZFM, DC, JHL; funding acquisition, DC and JHL. All authors have read and agreed to the published version of the manuscript.

\section{Acknowledgements}

The authors wish to acknowledge Prof. Lu Xiao (Science and Technology Development Center, Chinese Pharmaceutical Association), Prof. Wanyu Feng (Department of Pharmacy, Peking University People's Hospital), and Prof. Li Yang (School of Public Health, Peking University), for their help in study design. The authors are grateful to the staff in China Drug Supply Information Platform for their kind help in data collection.

\section{References}

1. Zhai T, Zhang Y, Wan Q, Chai P, Guo F, Li Y et al. The Results and Analysis of National Health Accounts in China in 2018. Chinese Health Economics. 2020;39(6):5-8. doi: 10.7664/CHE20200601.

2. National Health Development Research Center of the National Health Commission. 2018 China Total Health Expenditure Research Report. Beijing: Institute of health and economy press; 2018.

3. Gorske AL. A national survey of physician-industry relationships. N Engl J Med. 2007;357(5):508, 508

4. Norris SL, Holmer HK, Ogden LA, Burda BU, Fu R. Characteristics of physicians receiving large payments from pharmaceutical companies and the accuracy of their disclosures in publications: an observational study. BMC MED ETHICS. 2012;13:24. doi: 10.1186/1472-6939-13-24.

5. Fu H, Li L, Yip W. Intended and unintended impacts of price changes for drugs and medical services: Evidence from China. Social science \& medicine (1982). 2018;211:114-22. doi: 10.1016/j.socscimed.2018.06.007.

6. Yip W, Hsiao WC. The Chinese health system at a crossroads. Health Aff (Millwood). 2008;27(2):460-8. doi: 10.1377/hlthaff.27.2.460.

7. Dong W, Wang Y, Tang S, Zhu D, Lin S, Liang $\mathrm{H}$ et al. Patients hardly benefit from drug price reduction and hospital following higher price drugs: An analysis on penicillin prescription from 2000 to 2008 in Shanghai. Chinese Health Resources. 2010;13(04):158-61

8. National Healthcare Security Administration of the People's Republic of China. Announcement on the release of the cases on the medical insurance management and efficiency improvement (the first batch). 2020. http://www.nhsa.gov.cn/art/2020/8/14/art_14_3404.html. Accessed March 25, 2021.

9. General Office of the State Council of the People's Republic of China. Pilot Program for National Centralized Drug Procurement and Use. 2019. http://www.gov.cn/zhengce/content/201901/17/content_5358604.htm. Accessed January 9, 2021.

10. Joint Procurement Office. The results of $4+7$ city drug centralized procurement. 2018. http://www.smpaa.cn/gjsdcg/2018/12/07/8531.shtml. Accessed 25 Nov 2020.

11. Mao Z, Yang Y, Chen L. Reform of Drug Supply and Guarantee System in China: Policy Measures and Effects. In: Wang C, Liang W, editors. Development Report on Health Reform in China (2020): Beijing: 
Social Sciences Academic Press; 2020. p. 96-123.

12. Chang F. Analysis on the core elements of centralized drug procurement. Chinese Health Resources. 2021:1-5. doi: 10.13688/j.cnki.chr.2021.200774.

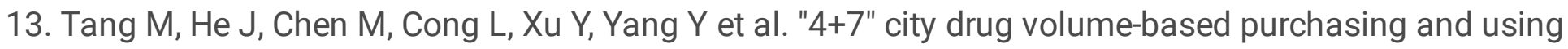
pilot program in China and its impact. Drug Discov Ther. 2019;13(6):365-9. doi:

10.5582/ddt.2019.01093.

14. Wang N, Yang Y, Xu L, Mao Z, Cui D. Influence of Chinese National Centralized Drug Procurement on the price of policy-related drugs: an interrupted time series analysis. Preprints. 2021;2021040157. doi: 10.20944/preprints202104.0157.v1.

15. Yuan J, Lu ZK, Xiong X, Jiang B. Lowering drug prices and enhancing pharmaceutical affordability: an analysis of the national volume-based procurement (NVBP) effect in China. BMJ Glob Health. 2021;6(9). doi: 10.1136/bmjgh-2021-005519.

16. Wen X, Yin S, Cui L, Mao L, Lin Z, Yaermaimaiti Z et al. The Effects of the National Centralized Drug Purchasing Pilot Program on Nucleos(t)ide Analogs in Shenzhen City: An Interrupted Time Series Analysis. Frontiers in Public Health. 2021;9. doi: 10.3389/fpubh.2021.718013.

17. Qu J, Zuo W, Wang S, Du L, Liu X, Gao Y et al. Knowledge, perceptions and practices of pharmacists regarding generic substitution in China: a cross-sectional study. BMJ OPEN. 2021;11(10):e51277. doi: 10.1136/bmjopen-2021-051277.

18. Wang J, Yang Y, Xu L, Shen Y, Wen X, Mao L et al. The impact of National Centralized Drug Procurement policy on the use of policy-related original and generic drugs in public medical institutions in China: A difference-in-difference analysis based on national database. medRxiv 2021.06.21.21256568. 2021. doi: https://doi.org/10.1101/2021.06.21.21256568.

19. Yang Y, Chen L, Ke X, Mao Z, Zheng B. The impacts of Chinese drug volume-based procurement policy on the use of policy-related antibiotic drugs in Shenzhen, 2018-2019: an interrupted time-series analysis. BMC Health Services Research (Preprints). 2021. doi: 10.21203/rs.3.rs-143454/v1.

20. Yu C. The practical effects and system concerns of "4+7" drug procurement. Journal of Southwest Minzu University (Humanities and Social Science). 2020;41(04):34-9

21. Chen L, Yang Y, Luo M, Hu B, Yin S, Mao Z. The Impacts of National Centralized Drug Procurement Policy on Drug Utilization and Drug Expenditures: The Case of Shenzhen, China. Int J Environ Res Public Health. 2020;17(24). doi: 10.3390/ijerph17249415.

22. Deng J, Tian H, Guo Y, Ma T, Sun Y, Zhang S et al. A retrospective and prospective assessment of the zero-markup drug reform in China from the perspective of policy diffusion. Int $\mathrm{J}$ Health Plann Manage. 2018;33(4):e918-29. doi: 10.1002/hpm.2562.

23. General Office of the State Council of the People's Republic of China. Guiding Opinions on Improving the Centralized Drug Procurement in Public Hospitals (Guobanfa [2015] No. 7). 2015. http://www.gov.cn/zhengce/content/2015-02/28/content_9502.htm. Accessed March 6, 2021.

24. Liu W, Hassan Gillani A, Xu S, Chen C, Chang J, Yang C et al. Antibiotics (Macrolides and Lincosamides) Consumption Trends and Patterns in China's Healthcare Institutes. Based on a 3 Year 
Procurement Records, 2015-2017. INT J ENV RES PUB HE. 2021;18(1):113. doi:

10.3390/ijerph18010113.

25. Wang Y, Wu Z. Keypoint Analysis of Monitoring Plan for Centralized Drug Purchase and Use Project Pilot Launched Organized by State. China Pharmacy. 2019;30(17):2317-22. doi: 10.6039/j.issn.1001-0408.2019.17.03.

26. Addis A, Magrini N. New approaches to analysing prescription data and to transfer pharmacoepidemiological and evidence-based reports to prescribers. PHARMACOEPIDEM DR S. 2002;11(8):721-6. doi: 10.1002/pds.785.

27. Han S, Wang T, Guan X, Li H, Xin X, Tian H et al. An analysis of the utilization of antacids and antiulcer drugs from 2007 to 2011 in Guangdong province of China. Chinese Journal of New Drugs. 2013;22(20):2358-64

28. Tang M, Han S, Wang R, Shi L, Sun L. Effects of Canceling Drug Price Addition Policy on the Change of Drug Structure in the Public Hospitals in Beijing City. Chinese Hospital Management. 2017;37(10):4-6

29. Wu J, Yue N. Index analysis of effect factor in pharmaceutical expenditure. Chinese Journal of New Drugs and Clinical Remedies. 2010;29(1):24-9

30. WHO Collaborating Centre for Drug Statistics Methodology. ATC/DDD Index 2021. 2021. https://www.whocc.no/atc_ddd_index/. Accessed March 6, 2021.

31. Shen M, Hu M, Zeng N, Sun Z. Application of the Difference-in-difference Model in Medical Research. Chinese Journal of Health Statistics. 2015;32(03):528-31

32. Ye F, Wang Y. Introduction and Application of the Difference-in-difference Model. Chinese Journal of Health Statistics. 2013;30(01):131-4

33. Wing C, Simon K, Bello-Gomez RA. Designing Difference in Difference Studies: Best Practices for Public Health Policy Research. ANNU REV PUBL HEALTH. 2018;39(1):453-69. doi: 10.1146/annurevpublhealth-040617-013507.

34. Zhang F, Wagner AK, Soumerai SB, Ross-Degnan D. Methods for estimating confidence intervals in interrupted time series analyses of health interventions. J CLIN EPIDEMIOL. 2009;62(2):143-8. doi: 10.1016/j.jclinepi.2008.08.007.

35. Hu R, Lin M. Application of Difference-Difference Method in Public Policy Evaluation. FINANCIAL MINDS. 2018;3(03):84-111

36. Zhao H, Wei L, Li H, Zhang M, Cao B, Bian J et al. Appropriateness of antibiotic prescriptions in ambulatory care in China: a nationwide descriptive database study. The Lancet Infectious Diseases. 2021. doi: https://doi.org/10.1016/S1473-3099(20)30596-X.

37. He J, Tang M, Cong L, Xu Y, Song J, Chen $M$ et al. The impact of National Centralized Drug Procurement on the clinical management and drug use. Chinese Health Resources. 2021:1-3. doi: 10.13688/j.cnki.chr.2021.200802.

\section{Figures}




\section{China Drug Supply Information Platform (CDSIP) database}

- 7647 drugs (by generic name)

- 141,624 products (by YPID code)

Drugs related to "4+7"policy

- 122 drugs ( 25 " $4+7$ " List drugs and 97 alternative drugs)

- 5906 products

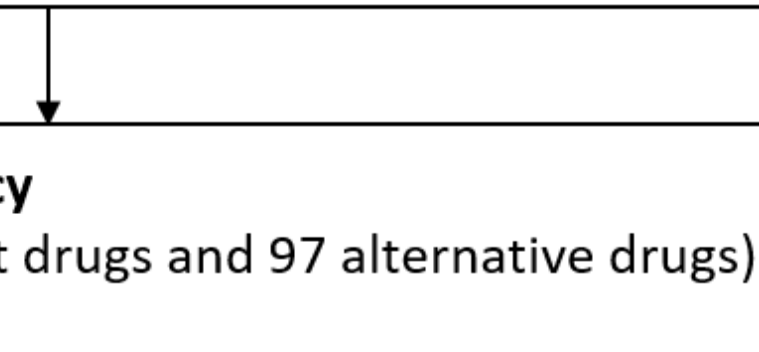

Policy-related drugs purchased in PG and CG from January 2018 to November 2019

- 122 drugs ( 25 " $4+7$ " List drugs and 97 alternative drugs)

- 4056 products

Exclude drug purchase orders did not come from 9 pilot cities and 12 control provinces.

\begin{tabular}{|l|l|} 
& $\begin{array}{l}\text { Select drugs purchased at } \\
\text { time in baseline-period an } \\
\text { reporting-period }\end{array}$ \\
Samples included in this study \\
• 108 varieties ( 25 " $4+7$ " List drugs and 83 alternative drugs) \\
- 2562 products
\end{tabular}

\section{Figure 1}

The flow chart of the sample selection process. 


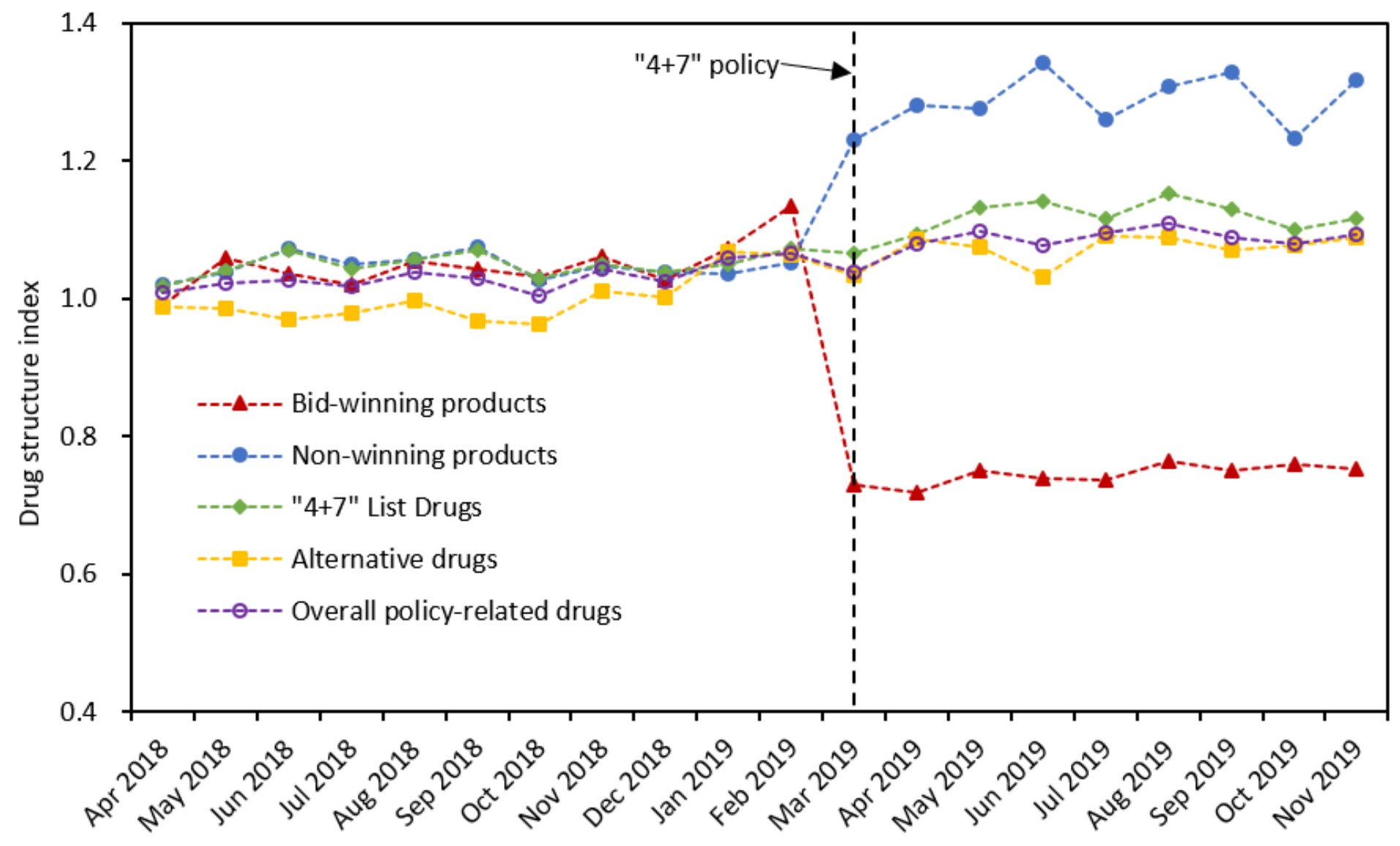

Figure 2

presents the monthly trend of DSI of policy-related drugs in 9 pilot cities from April 2018 to November 2019.

\section{Supplementary Files}

This is a list of supplementary files associated with this preprint. Click to download.

- supplementaryfile.docx 